\title{
El tiempo vuela: el uso de aves y otros animales para representar las unidades de tiempo de la cuenta larga maya
}

Time flies: the use of birds and other animals to represent the units of time in the Maya Long Count

Le temps "vole ": l'usage des oiseaux et autres animaux pour représenter les unités de temps dans le Compte long maya

\section{Rogelio Valencia Rivera}

\section{OpenEdition}

\section{Journals}

Edición electrónica

URL: http://journals.openedition.org/jsa/15310

DOI: $10.4000 /$ jsa. 15310

ISSN: $1957-7842$

Editor

Société des américanistes

Referencia electrónica

Rogelio Valencia Rivera, « El tiempo vuela: el uso de aves y otros animales para representar las

unidades de tiempo de la cuenta larga maya », Journal de la société des américanistes [En línea], Maya times | 2017, Publicado el 31 diciembre 2017, consultado el 19 abril 2019. URL : http:// journals.openedition.org/jsa/15310; DOI : 10.4000/jsa.15310 


\title{
El tiempo vuela: el uso de aves y otros animales para representar las unidades de tiempo de la cuenta larga maya
}

\author{
Rogelio Valencia Rivera*
}

\begin{abstract}
El uso de imágenes zoomorfas para representar los distintos periodos que se emplean en la cuenta larga de los mayas no ha podido ser explicado en su conjunto, y no se ha logrado comprender su significado de manera satisfactoria. La propuesta del presente trabajo es que los animales que fueron utilizados para representar cada uno de los periodos tienen una característica en común: todos tienen una relación estrecha con los fenómenos naturales asociados con la lluvia. Algunos representan las corrientes de agua generadas por la lluvia, otros anuncian su llegada o están asociados con los vientos que traen las tormentas. Esto nos permite inferir que el año calendárico en el área maya fue fijado con respecto a las temporadas de lluvias y no con respecto al ciclo solar. Esta hipótesis clarifica el origen de la palabra haab', "año" que aún conserva su acepción de "lluvia" o "tormenta" en algunas lenguas mayas. [Palabras claves: calendario maya, cuenta larga, haab', temporada de lluvias, mono, batracio, ave.]
\end{abstract}

Time flies: the use of birds and other animals to represent the units of time in the Maya Long Count. The zoomorphic images used to represent the different periods that form the Mayan Long Count have never been explained in a global way and their meaning remains poorly understood. This paper argues that the animals used to represent the periods of the Long Count have a common characteristic: all of them show a very strong relationship with the natural phenomenas associated with rain. Some represent the water currents generated by downpours, others announce the arrival of the storms, or are associated with the winds that bring them. This relationship lets us infer that, in the Maya area, the calendric year was fixed in association to the rainy season and not to the solar transit. This hypothesis clarifies the origin of the word, haab', "year", which even nowadays has the meaning of "rain", or "storm" in some Mayan languages. [Key words: Maya calendar, Long Count, haab', rainy season, monkey, toad, bird.]

Le temps «vole»: l'usage des oiseaux et autres animaux pour représenter les unités de temps dans le Compte long maya. L'usage d'images zoomorphes pour représenter les différentes périodes qui interviennent dans le Compte long maya n'a pas pu être

* Investigador independiente, México [rogelio.valencia.rivera@gmail.com]. 
expliqué de façon globale et la signification de ces images n'est pas comprise de façon satisfaisante. Le présent travail propose que ces animaux ont été choisis pour représenter chaque période en raison d'une caractéristique commune : tous entretiennent, en effet, une étroite relation avec des phénomènes atmosphériques associés à la pluie. Quelquesuns renvoient aux cours d'eau alimentés par la pluie, d'autres annoncent l'arrivée de la pluie ou sont associés aux vents qui la véhiculent. Cela nous permet d'inférer que l'année calendaire a, dans l'aire maya, été fixée par rapport à la saison des pluies. Et cette hypothèse clarifie aussi l'origine du mot haab', "année», qui, encore aujourd'hui, conserve le sens de «pluie» ou de «tempête» dans quelques langues mayas. [Motsclés : calendrier maya, Compte long, haab', saison des pluies, singe, batracien, oiseau.]

\section{Introducción}

En sus orígenes, la cuenta larga (Figura 1), creada por la cultura epi-olmeca (Stuart 2011, p. 173), simplemente indicaba un conjunto de cinco coeficientes para establecer el número de días transcurridos desde una fecha inicial determinada, denominada comúnmente "Fecha Era", situada hacia el 13 de agosto de 3114 a. C. El primero de dichos coeficientes indicaba el número de días de la fecha; el segundo indicaba el número de meses, cada uno de 20 días; el tercer coeficiente indicaba el número de años, compuestos a su vez por 18 meses; el cuarto coeficiente indicaba el número de veintenas de años; y el quinto coeficiente indicaba el número de veintenas de dichos grupos de veinte años, es decir, conjuntos de cuatrocientos años. Este calendario pasó posteriormente a las culturas del Pacífico guatemalteco para, más tarde, introducirse en el área maya (Ayala 1983, p. 202; Lacadena 2011; Stuart 2011, p. 175).

Es así como los mayas, con el fin de poder llevar la cuenta de sus días, adoptan el sistema de cuenta larga empleado por las culturas mixe-zoqueanas (Tellenbach 1977, p. 63; Stuart 2011, p. 173-175). Ya en el área maya, los coeficientes de la cuenta larga adquieren una denominación autóctona, siendo $k$ 'in el nombre asignado para los días, winik o winal para los meses, haab' para los años, winikhaab' para las veintenas de años, y pik o pih para los periodos de 400 años (Stuart 2011, p. 172).

Posteriormente, los mayas adaptaron dicho calendario a su entorno cultural, si bien respetando los principios básicos de su funcionamiento para registrar el transcurso del tiempo. Las lenguas mayas, al carecer de especificaciones de tiempo para los verbos, -pues solamente indican la voz y el aspecto de las acciones indicadas por éstos-, necesitan de algún mecanismo que permita fijar el momento en que los eventos descritos en los monumentos ocurren. Es posible que debido a esta carencia, se le diera tanta preponderancia al uso de la cuenta larga en la mayor parte de las inscripciones del periodo clásico, pues era el medio a través del cual se podían anclar los eventos en el tiempo. Es así 
como, una vez incorporada por la cultura maya, la cuenta larga sufre algunas alteraciones y modificaciones, siendo las más importantes las siguientes.

- Un cambio de los patronos del mes. De acuerdo con Justeson y Kaufman (1992, p. 22), la correlación de las fechas del calendario epi-olmeca debería situarse veinte días antes que la que establecen Goodman, Martínez y Thompson en su correlación para el calendario maya, pues los patronos del mes en el calendario maya están desfasados un mes con respecto al calendario mixe-zoqueano. Ésta no es la única evidencia de dicho cambio, ya que, de acuerdo con los mencionados investigadores, las fechas indicadas en la Estela 1 de La Mojarra están vinculadas con la elongación máxima vespertina de Venus, pero sólo si se emplea la fecha corregida. Es así como plantean que la Fecha Era epi-olmeca estaría situada en 13.0.0.0.0 4 Ajaw 8 K'ayab', es decir el 24 de julio de 3114 a. C.

- La introducción del empleo de ciclos temporales por encima de los cinco ya mencionados, utilizando múltiplos de trece sobre el último de aquéllos con el fin de representar tiempos mitológicos o muy profundos en el tiempo (Stuart 2012).

- La creación de un cero posicional cuya primera aparición ocurre hacia $357 \mathrm{~d}$. C. en las Estelas 18 y 19 de Uaxactun (Davletshin 2002). Es muy probable que dicho cero posicional existiera también dentro de la cultura epi-olmeca, pues el sistema de notación calendárica así lo requiere para indicar fechas de fin de ciclo, pero éste no fue registrado en ningún ejemplo, o no ha sido constatado así por el momento. La aparición de este cero en las inscripciones mayas pudo deberse a un cambio ideológico, pues ya durante el Clásico tardío se da preferencia a la erección de monumentos en los finales de periodo, dotándoles de una gran carga ritual (ver Cases, Lacadena y Nondedeo 2014; Stuart 1996).

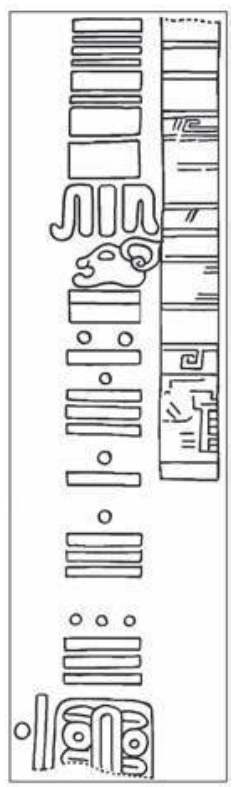

Fig. 1 - Estela C de Tres Zapotes, Veracruz. Ésta es la inscripción completa más temprana que se conoce con Cuenta larga, con la fecha 7.16.6.16.18, $6 \mathrm{Etz}$ 'nab' [1 Wo ] (según Tellenbach 1977, Fig. 4) ${ }^{1}$.

1. En realidad, la estela con la fecha más temprana sería la 2 de Chiapa de Corzo (Pérez 2012, p. 8), lugar situado en la zona fronteriza entre las regiones maya y mixezoque, pero ésta no se encuentra completa y la fecha ha tenido que ser reconstruida (Stuart 2011, p. 174). 
- La introducción de la serie complementaria, con ejemplos ya desde el Clásico temprano. En la Estela Hauberg se pueden apreciar algunos de sus elementos tales como el Glifo G y el glifo del semestre lunar, así como en la estela de El Encanto, fechada hacia 305-308 d. C. (Martin 2000, p. 52).

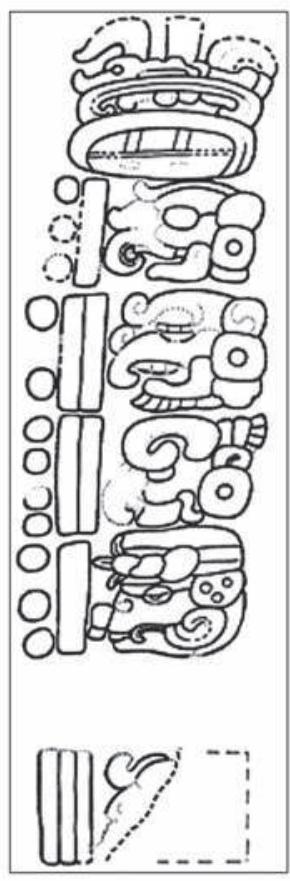

Fig. 2 - Estela 29 de Tikal con la fecha en cuenta larga de 8.12.14.8.15,

5 Men 8 K'umk'u (según Jones y Satterthwaite 1982, p. 61).
- Un cambio en el orden en la cuenta calendárica de Haab'-Tzolk'in a Tzolk'in Haab' (Martin 2000, p. 52).

- Una de las adecuaciones más interesantes que introdujeron los mayas en la cuenta larga fue el empleo de representaciones de animales para cada uno de los periodos que la conforman (Stuart 2011, p. 175176). Desde las inscripciones del Clásico temprano, pues aparecen por primera vez en la Estela 29 de Tikal (Figura 2), fechada de 292 d. C., hasta el Clásico tardío, los mayas incorporan el uso de criaturas zoomorfas para darle imagen a los diferentes periodos del tiempo contenidos en la cuenta larga. Es así como nos encontramos con imágenes de aves, serpientes acuáticas, batracios y monos. Hasta el momento, no se ha podido explicar la selección de este conjunto de seres para aparecer agrupados en este contexto. En este artículo me centraré específicamente en este último punto, con el fin de intentar explicar el uso de este conjunto particular de animales para representar los periodos que componen la cuenta larga.

\section{Los animales de la cuenta larga}

Para algunos investigadores, el empleo de animales dentro de la cuenta larga obedece a que estas representaciones serían las "personificaciones" de los periodos que la conforman (Lounsbury 1978, p. 767). Curiosamente, los glifos zoomorfos empleados para designar los distintos periodos sólo han sido analizados de forma aislada (Milbrath 1999; Rice 2007; Thompson 1950). Este acercamiento no permite la realización de un análisis basado en una comprensión del conjunto de los elementos zoomorfos de la cuenta larga, aplicando un análisis contextual (Valencia 2013, 2015). 
Además de los logogramas zoomorfos antes descritos, existe otro conjunto de logogramas que fueron empleados para designar a los periodos por su nombre. Tal es el caso del signo empleado para indicar los días, el glifo T544 en el catálogo de Thompson (1962), el cual ha sido identificado como una flor de cuatro pétalos y que, para algunos autores (Milbrath 1999, p. 58; Thompson 1950, p. 142), sería la plumería (Plumeria alba) aunque puede ser una forma convencionalizada de representar al propio sol, el cual despliega cuatro rayos.

Dichas variantes no se analizarán en este trabajo, ya que se suelen emplear también fuera del contexto de la cuenta larga. Es por ello que me centraré solamente en los glifos zoomorfos, de los cuales se intentará brindar una visión de conjunto respecto a su posible significación, pero primero se verá a cada uno de ellos por separado con el fin de definirlos correctamente.

\section{El mono}

El primer número de la cuenta larga se empleaba para indicar el número de días de una fecha, denominado k'in, o "día" en maya (Figura 3). Este periodo fue regularmente representado por el glifo de un mono (Coe 1977, p. 341), así como por el logograma convencional para el sol del que se habló en la sección anterior. En ningún caso registrado, el glifo del mono lleva complementación fonética alguna, por lo que no podemos asegurar que se leyera como $k$ 'in.
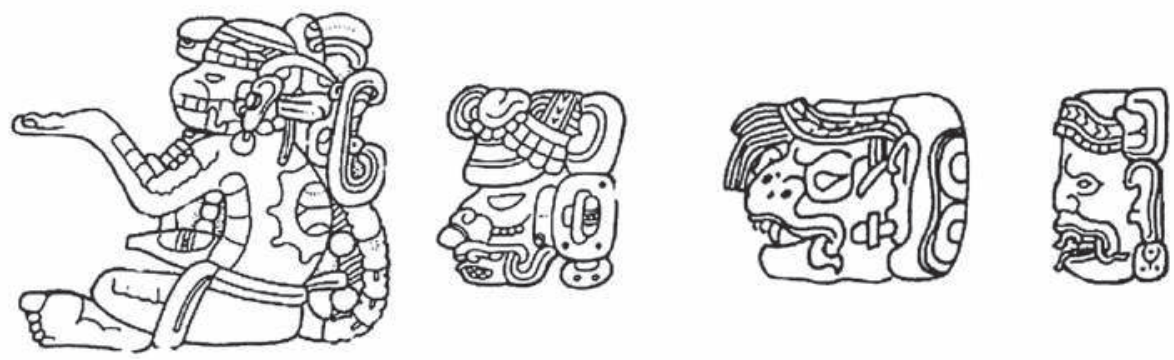

Fig. 3 - Ejemplos del glifo para la posición de los días, $k$ ’in, en la cuenta larga en sus variantes de cuerpo completo y de cabeza (Lacadena et al. 2010).

Una explicación, que algunos investigadores le dan al hecho de que el mono aparezca como una representación del día, es que el mono tiene un carácter o aspecto mitológico solar (Milbrath 1999, p. 92), o que, debido a su carácter mántico ${ }^{2}$ dentro del calendario, al ser el día Chuwen en las Tierras Bajas

2. Mántica: (del griego $\mu \alpha v \tau \imath \kappa \eta ́$, arte de la adivinación). Conjunto de prácticas mediante las cuales se trataba de adivinar el porvenir (Diccionario de la Real Academia de la Lengua). 


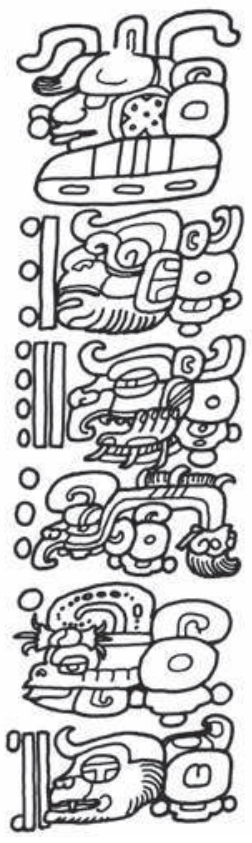

Fig. 4 - Placa de Leiden con la fecha 8.14.3.1.12, 1 Eb' 0 Yaxk'in (según dibujo de Linda Schele). del Norte o Baatz' en el resto de los sitios mayas, es el encargado de fijar el punto determinante en una fecha calendárica dada (Braakhuis 1987, p. 28-29).

En realidad, el mono parece estar más asociado culturalmente, dentro del área maya, con el cacao y la escritura. Su asociación con el cacao se debe, probablemente, al hecho de que se alimenta con asiduidad de dicho fruto y es fundamental en la dispersión de sus semillas (Nájera 2012). Su asociación con la escritura parece situarse dentro de la concepción mítica del origen de ésta, siendo la explicación más plausible la ofrecida por el Popol Vuh, según la cual los hermanos de Hunahpu y Xb'alamke, Hunbatz y Hunchuen, se convierten en monos debido a su comportamiento errático y se vuelven patrones de las artes y, en específico, de la escritura (Coe 1977, p. 341).

La especie de mono representada en las inscripciones de cuenta larga, que suele aparecer con una figura antropomorfa, es el mono aullador, o saraguato, pero en algunas

ocasiones, también se representa al mono araña (Braakhuis 1987, nota 11), como en la inscripción de la placa de Leiden (Figura 4), donde se puede apreciar el fleco de pelos sobre su frente, característico de esta especie de primate. En este mismo ejemplo, el ojo del mono presenta un signo que bien pudiera ser el signo Chuwen, pero que, en mi opinión, es en realidad una variante del glifo IK', "viento", elemento que analizaremos con detenimiento más adelante, pues resulta de especial interés para este estudio.

En algunos casos, el animal que aparece en la posición de los días se ha identificado con un zorro, y en otros con un mono capuchino (Baker 1992, p. 219, 225; Milbrath 1999, p. 92), animal que no habita la región maya. A las características físicas del hocico de algunas de sus representaciones, como la del Dintel 48 de Yaxchilán (Figura 5).

En estos casos, es muy probable que se trate de otro animal de la región que posee cola prensil y que vive en las copas de los árboles, tal como el mico de noche, también llamado kinkajú o martucha. Esto nos indica que se han venido empleando clasificaciones taxonómicas occidentales para tratar de comprender el universo natural maya y éste dista mucho de 
ser como el nuestro. Parece claro que, dentro de la mentalidad maya del periodo clásico, cualquier animal que viviese en los árboles y tuviera una cola prensil estaba integrado dentro del mismo grupo taxonómico que el mono araña y el saraguato.

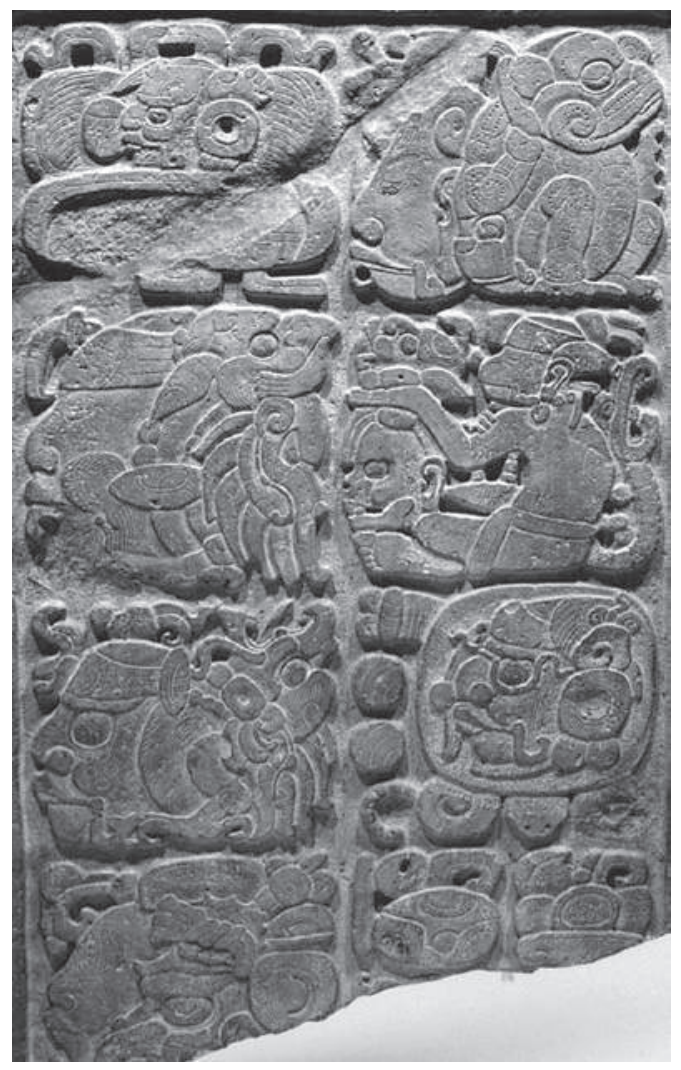

Fig. 5 - Dintel 48 de Yaxchilán, con fecha 9.4.11.8.16, 2 Kib’ 19 Pax, 11 de febrero de 526 d. C. (según foto INAH).

Otro caso que nos permite validar esta idea de las diferencias entre las clasificaciones taxonómicas maya y occidental, es el de los caimanes y cocodrilos, ya que, dentro de la cultura maya, tampoco se les diferencia, sino que constituyen un único grupo o especie (Salazar Lama 2014, p. 159-163). Otro detalle interesante es que veían las colas de los monos como un ser animado independiente (ver al mono de cuerpo completo en la Figura 3), que en ocasiones era representado como una serpiente o bien como un ciempiés (Taube 2003, p. 413). 


\section{El sapo y la rana}

El siguiente elemento de la cuenta larga, el de los meses, denominado en maya clásico winik o winal, fue representado usualmente mediante la imagen de un batracio (Figura 6).
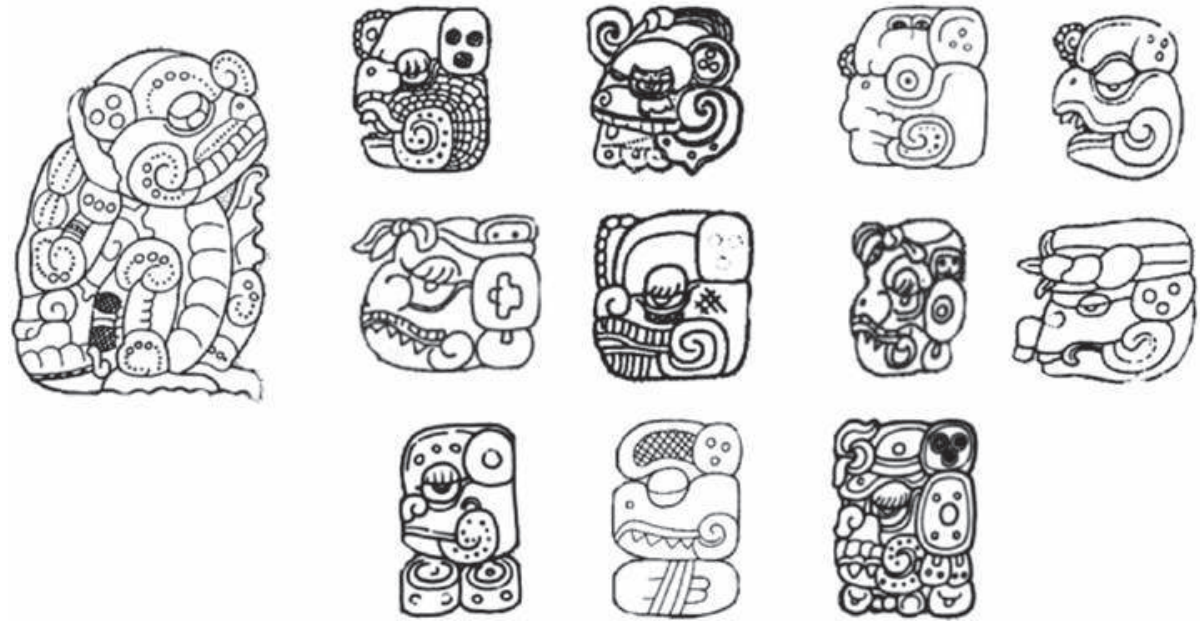

Fig. 6 - Ejemplos del glifo para la posición de los meses en la cuenta larga.

Variantes de cuerpo completo y de cabeza (Lacadena et al. 2010).

Como se puede apreciar en la Figura 6, en algunos de los ejemplos el logograma del batracio lleva un complemento fonético que puede ser -ki, para leer winik, o -la, para leer winal, según la variante dialectal ch'olana de que se trate (Lacadena y Wichmann 2002, p. 291). El batracio regularmente mostrado en las inscripciones de cuenta larga parece ser el Bufo marinus, pues se representa con un círculo cerca de la cavidad auricular, que a menudo presenta tres puntos en su interior, y que hace referencia a la glándula parótida del animal. Es un sapo de gran tamaño que, además, posee dos glándulas venenosas. Otro batracio fuertemente asociado con aspectos mitológicos en el área maya es el denominado uo, llamado así por el sonido que emite.

\section{La serpiente de agua}

El siguiente ciclo dentro de la cuenta larga, el del haab', puede estar representado por un ave o por una serpiente de características especiales, denominada en los estudios mayas como la Serpiente Lirio Acuático (Figura 7). 


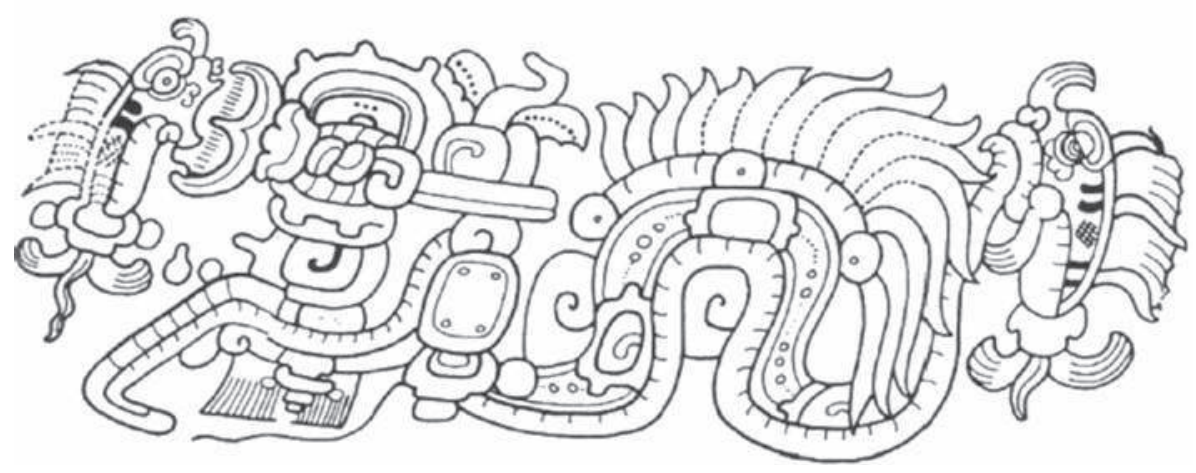

Fig. 7 - Serpiente acuática - WITZ’ (Hellmuth 1987, p. 161, fig. 321).

Su nombre en el maya clásico fue leído por Stuart en 2007 como witz', que significa “cascada" en ch' orti (Wisdom 1950) y que en yucateco colonial significa "salpicar con un líquido" (Barrera V. 1980, p. 925). Se representa como una serpiente sin mandíbula inferior, que, además, porta un tocado con forma de lirio acuático del cual suelen comer pequeños peces. Este ser mitológico aparece en ocasiones como sustituto del signo IMIX, el cual se lee como ha', "agua". Su nombre en ocasiones va sufijado por el sustantivo Naah Chan, indicando que es una serpiente grande, como en la Estela 2 de Bonampak. También funciona en ocasiones como el número 13, tal y como se puede apreciar en la Estela D de Quiriguá (Zamora 2008, p. 102).

Un detalle importante en relación con este logograma que representa al periodo del haab' (Figura 8), es que nunca aparece con complementación fonética alguna que permita inferir que se leía efectivamente como haab', y tampoco existe indicación alguna que permita deducir que el signo del año se leía como witz' cuando se empleaba este glifo (Stuart 2007).
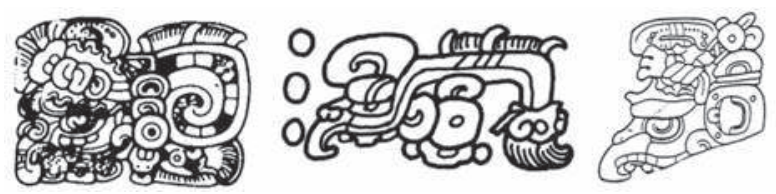

Fig. 8 - Ejemplos del logograma WITZ', a. Copán. Estela 63

(Stuart et al. 1989, fig. 1), b. Placa de Leiden (dibujo de Linda Schele), c. Yaxchilan. Dintel 48 (dibujo de Ian Graham).

\section{Las aves}

Los animales empleados para representar los últimos tres ciclos de la cuenta larga, correspondientes al haab', al winikhaab'y al pik, son tres aves mitológicas. 
Se indica que son mitológicas debido a que, dadas las características físicas con las que son representadas, no se puede hacer una identificación de éstas con aves existentes en el área maya.

La del haab' es un ave con características de rapaz, debido a su pico curvo, pero que posee la mandíbula inferior descarnada, de la misma forma en que se emplea para representar los numerales en forma de cabeza que están por encima del número doce, además del número diez (Figura 9).
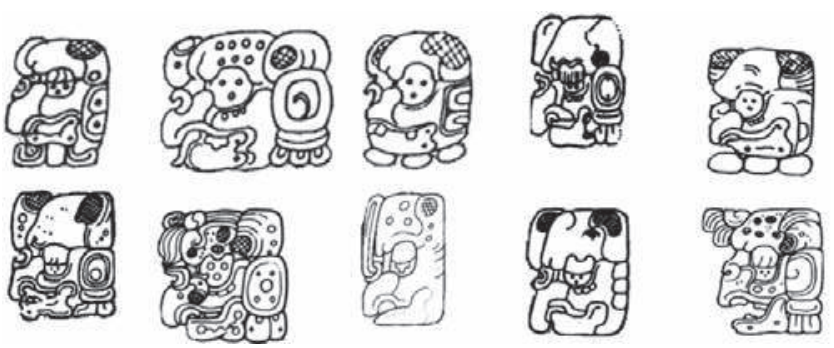

Fig. 9 - Ejemplos del glifo empleado para la posición de los años, haab', en la cuenta larga (Lacadena et al. 2010).

Esta mandíbula se ha tomado como una representación de la muerte, como elemento que completa o complementa el tiempo de la vida (Stuart 2014) al indicar como rebus la palabra laj, "completar, se acaba" (Weathers y Weathers 1949, p. 39), integrada en el numeral lajun, "diez". De la misma forma que para el número diez, implica de cierta forma un ciclo completo, y una reminiscencia decimal dentro del sistema numérico vigesimal maya (con excepción de los números once y doce que no integran la mandíbula descarnada). Esto significaría que el año es el elemento completo sobre el cual gira la cuenta larga.

Otros investigadores ya habían indicado este hecho (Rice 2007, p. 176; Thompson 1950, p. 141-142). Stuart (2011, p. 168) lo justifica, indicando que a partir de la cuenta de años, el sistema numérico que rige el calendario maya es auténticamente vigesimal, de forma que el haab' constituye la fundación conceptual para todo el calendario. Otro elemento que parece apuntar a este núcleo conceptual de la cuenta larga alrededor del haab' es el hecho de que el nombre jeroglífico para el periodo superior sea $P i k$, palabra equivalente a 8000 (Stuart 2011, p. 173), ya que indicaría el tercer orden de magnitud dentro de un esquema vigesimal ( $20 \times 20$ × 20$)$ y no el quinto, posición que realmente ocupa dentro de la cuenta larga. Una posible validación para esta idea proviene del hecho de que precisamente los tres órdenes superiores de la cuenta larga son representados en las inscripciones mediante la imagen de un ave, lo cual proporciona una correlación entre el tipo de representación y la idea de tres 
órdenes vigesimales de magnitud. Esta derivación de los signos para representar los dos órdenes superiores a partir de uno básico para el haab ' ya había sido comentada por Justeson et al. (1985, p. 76).

El ave empleada para representar al haab' ha sido identificada por algunos autores como la mítica ave Muwaan, empleada para nombrar uno de los meses del año (Thompson 1950, p. 145). Aunque el ave del haab' posee en algunas de sus representaciones las plumas con pintas negras a los lados de la cabeza, no parece ser la misma ave, pues nunca aparece con plumas en la boca (Figura 10).
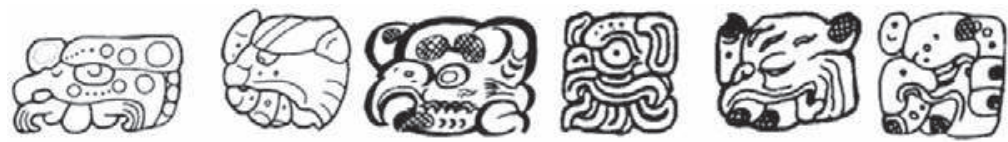

Fig. 10 - Ejemplos del glifo del logograma MUWAN (Lacadena et al. 2010).

Otro detalle que permite eliminar esta posibilidad son los tres puntos que el ave del haab' posee en el ojo y que nunca porta el ave Muwan. Esta característica relaciona al ave del haab' con el felino denominado hix durante el Clásico, por lo que en realidad es probable que este ser sea una mezcla de ave y felino. Este glifo suele llevar en ocasiones una complementación fonética en -ma, lo cual podría indicar una fosilización epigráfica de cuando se empleaba la sílaba $m a$ como sustitución de la sílaba $b$ 'a, la cual se emplearía para indicar la consonante final de la palabra haab'. De acuerdo con Lacadena (2010, p. 35), las sílabas con la consonante "b" no existían dentro del lenguaje del que proviene el sistema de escritura que sirvió de base al silabario maya, el mixe-zoque y eran representadas mediante los signos para las sílabas con la consonante "m". Esta misma complementación fonética la suele llevar el logograma del año, T548, HAB', por lo que parece razonable asumir que se emplea para lo mismo.

Como ya habíamos mencionado, para el winikhaab' también contamos con el glifo de un ave para representar dicho periodo. Esta ave también parece una rapaz, pero se caracteriza por llevar la marca de objetos brillantes, tales como espejos u objetos de jade, infija en la cabeza. Este mismo logograma, el ave rapaz con el espejo en la cabeza, se lee como $\mathbf{C H A N}$, "cielo", en contextos ajenos a la cuenta larga (Figura 11, página siguiente).

La complementación fonética que va con este glifo es muy interesante, pues en algunos de sus ejemplos es idéntica a la que presenta el glifo del año para indicar la lectura winikhaab'. Esto puede significar que el ave rapaz con espejo en la frente se lee como HAB', además de la lectura que posee como CHAN o quizás simplemente se emplee la complementación fonética para indicar que se trata del periodo correspondiente a los winikhaab', sin tener nada que ver 


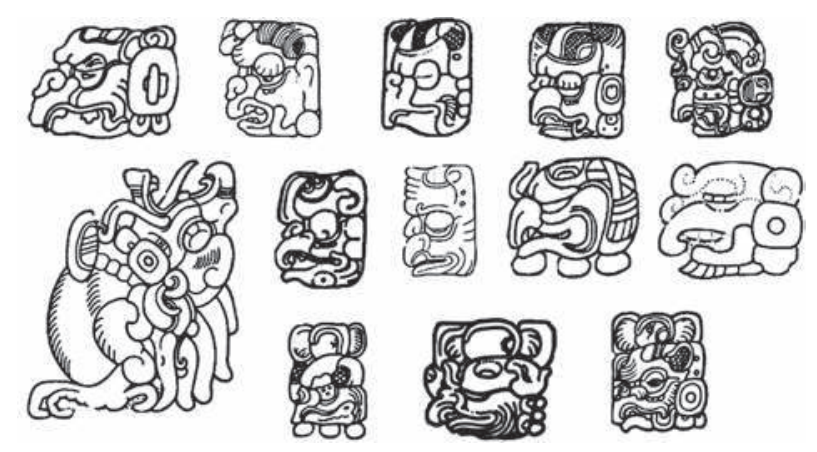

Fig. 11 - Ejemplos del glifo para la posición de los Winikhaa'b en la cuenta larga, en sus versiones de cuerpo entero y de cabeza (Lacadena et al. 2010).

con la lectura de la cabeza del ave, esto con el fin de diferenciarla de las otras aves que aparecen en la cuenta larga.

Finalmente tenemos al ave que representa el último de los periodos normales en la cuenta larga, el antes denominado bak'tuun y que ahora sabemos que se leía como pik, o pih, en el periodo clásico. Aquí también aparece representada un ave rapaz, cuya mandíbula inferior ha sido sustituida por una mano, idéntica a la empleada para ciertas variantes de cabeza del número cero y cuyo significado desconocemos (Figura 12).
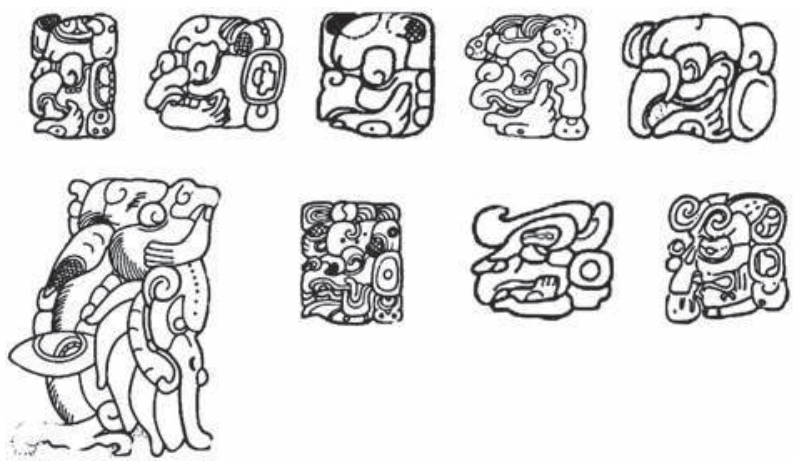

Fig. 12 - Ejemplos del glifo para la posición de los Pik en la cuenta larga en sus versiones de cuerpo entero y de cabeza (Lacadena et al. 2010).

Pareciera que en algunas ocasiones, como se puede ver en la figura 12, el glifo del ave lleva la complementación fonética - $h i$, indicada por el nudo de 
fibras que lleva el ave sobre la cabeza. Esta complementación posiblemente se empleaba para señalar la consonante final de la palabra pih. Pero también es verdad que hay ejemplos, como los de las Estelas 9, 13 y 15 de Copán, donde todas las aves que forman la fecha en la cuenta larga tienen ese mismo atado de fibras sobre la cabeza, por lo que no se puede asegurar que éste realmente opere como un signo jeroglífico llevando a cabo una complementación fonética.

Un detalle interesante acerca de esta ave es que aparece representada en bandas celestes como la del relieve de estuco del Edificio Margarita en la Acrópolis de Copán (Figura 13), en el mascarón de la Estructura Bayal, en la Acrópolis Los Árboles, de Xultún (Rivera Castillo y Saturno 2012, p. 563) y en el mascarón de K'inich en la Estructura Yehnal (Figura 14, página siguiente), en la Acrópolis de Copán³.

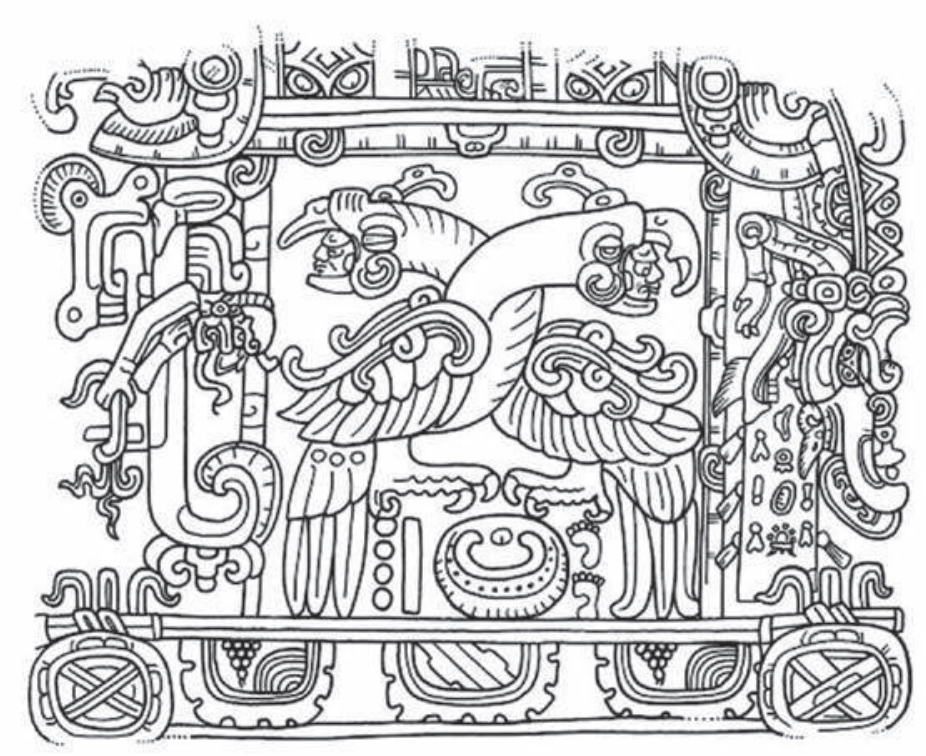

Fig. 13 - Relieve de estuco del Edificio Margarita en la Acrópolis de Copán. Dibujo de Salazar Lama (2014, fig. 4.23B), basado en el levantamiento 3D de Tokovinine (2013).

3. Agradezco a Daniel Salazar Lama que llamó mi atención acerca de la existencia de estos ejemplos y me facilitó sus dibujos de los mismos. 


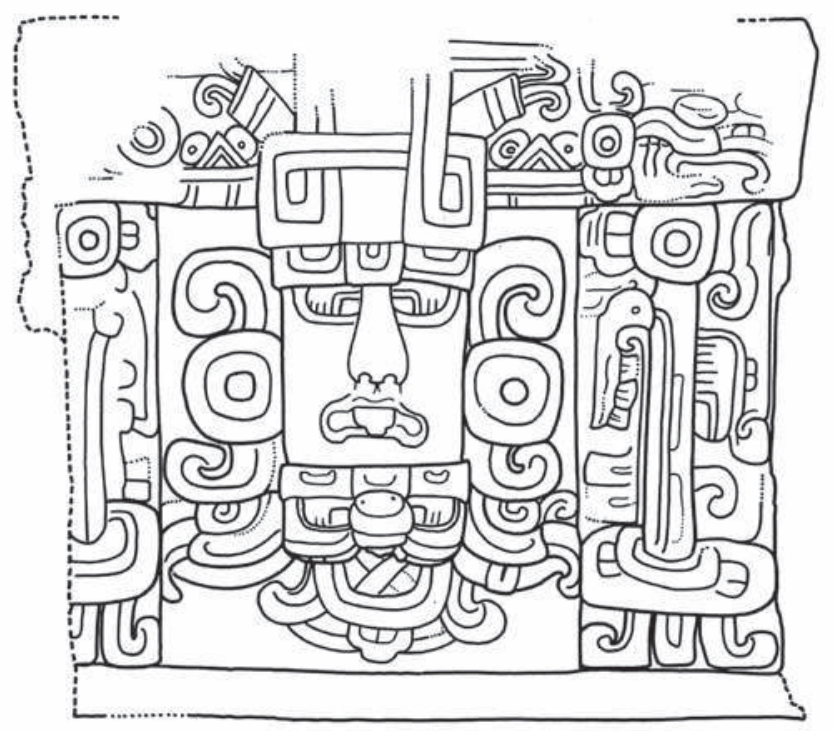

Fig. 14 - Mascarón de K'inich Ajaw en la Estructura Yehnal en la Acrópolis de Copán. Dibujo de Daniel Salazar Lama (2014, fig. 4.7D).

Es muy probable que en este contexto, el ave sirva para denotar alguna característica especial que posee la banda celeste que la incluye, ya que en los casos de Copán podemos apreciar que solamente se incluyen símbolos de estrella en la propia banda, mismos que la definen como un espacio celestial. De hecho, es muy probable que el ave con la mano en la mandíbula sirva para hacer un mayor énfasis sobre la banda como un ámbito celeste y que su valor de lectura sea también CHAN (Valencia Rivera y Salazar Lama 2017).

Pese a que estos elementos gráficos de representación de los periodos aparecen desde épocas muy tempranas en las inscripciones mayas con fechas en el calendario de cuenta larga, también tenemos los logogramas que nos dan los valores de lectura para los nombres con los que se designa a dichos periodos. En muchos casos, como en el del mono, en el de la serpiente de agua y en el de las aves, la complementación fonética no parece indicar que la lectura de estos glifos sea equivalente a la de los logogramas que nombran los periodos. Sólo en el caso del batracio tenemos una complementación fonética que hace equivalente su valor de lectura con el del logograma uinik o uinal. Pero no hay que descartar la posibilidad de que ésta sea una asimilación tardía de un término en el otro, pues ningún ejemplo del Clásico temprano posee complementación fonética alguna y en algunos casos, jamás se intentó integrar la complementación fonética para indicar valores equivalentes de lectura. Tal es el caso del 
mono, que jamás lleva complementación en -ni, o el de la serpiente de agua que nunca lleva una complementación fonética que permita inferir que se leía como haab' en este contexto.

\section{Una visión de conjunto}

Para poder analizar la razón de la utilización de este conjunto específico de animales o seres mitológicos para representar los diferentes ciclos de la cuenta larga maya, lo primero que hay que preguntarnos sería: ¿Qué tienen en común? A primera vista, podría parecer que poco o nada, pero si observamos más detalladamente y analizamos en profundidad el simbolismo asociado a cada uno de estos seres, veremos que ciertamente tienen una característica compartida, la cual los relaciona además con los ciclos calendáricos. A continuación detallamos este análisis.

Las ranas y los sapos fungen como símbolos del agua y de la lluvia, no sólo en el área maya, sino en toda Mesoamérica. Dentro de la cultura mexica estaban asociados al dios Tlalok, tal y como se puede apreciar en la Figura 15, donde una rana porta una máscara con la cara de este dios. Esto se menciona tanto en fuentes documentales de la época colonial temprana, como en la etnografía actual, donde se les considera los voceros de los dioses pluviales que anuncian las lluvias con su canto (López Austin y López Lujan 2011, p. 304).

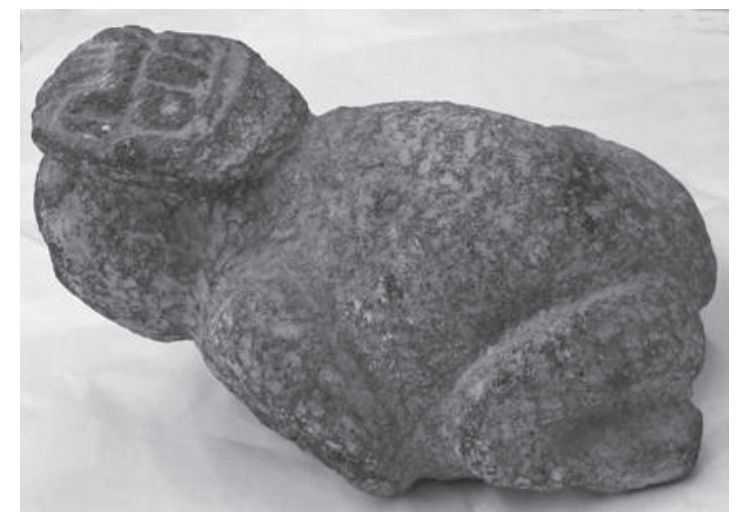

Fig. 15 - Rana con máscara de Tlalok, Museum für Völkerkunde, Viena ${ }^{4}$ (fotografía del autor).

4. Agradezco a Gerard W. van Bussel, responsable de las colecciones del Norte y Centroamérica del Museum für Völkerkunde de Viena por haberme permitido realizar fotografías de esta pieza. 
Estos animales también están presentes en el denominado "Altar de las Ranas", que demarca el espacio dedicado a Tlalok dentro del Templo Mayor de la Ciudad de Tenochtitlan (Figura 16). El análisis de los restos de pigmento en estas esculturas indicó que su cuerpo era azul, lo cual acentúa su conexión con Tlalok, pues este color está estrechamente relacionado con este dios y con la lluvia (López Austin y López Lujan 2011, p. 303).

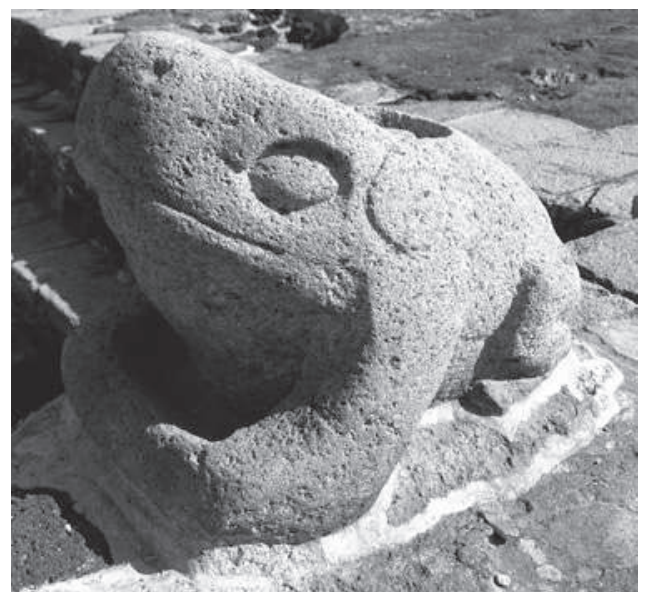

Fig. 16 - Rana perteneciente al Altar de las Ranas, Templo Mayor de Tenochtitlan (fotografía del autor).

El comportamiento de las ranas está regido en gran medida por los ciclos de las lluvias ya que, en las regiones tropicales y subtropicales, muchas especies se aparean de manera continuada durante la temporada de tormentas (Wells 2007, p. 340). Esto se debe a que la presencia de las lluvias les permite depositar sus huevos en las aguadas, aumentando con ello las posibilidades de supervivencia de sus crías, las cuales necesitan del agua para vivir cuando son renacuajos, pues carecen de pulmones después de salir del huevo.

El poder predictivo del canto de ranas y sapos en relación con la proximidad de las lluvias fue muy importante para los antiguos pueblos de Mesoamérica. En ciertas comunidades se les denomina "hijos de la lluvia", o proveedores de la misma. En las comunidades mayas, a la rana uo se le considera el músico de Chaahk, dios de la lluvia, pues canta cuando va a llover (Tuz Chi 2009, p. 38). Su conexión con el pronóstico de las lluvias se encuentra muy extendido por toda Mesoamérica.

Esto ha producido que en el área maya, los anfibios se relacionen con la actividad agrícola porque "si se oye cantar al sapo es que la lluvia va a llegar" (Tuz Chi 2009, p. 175). Dentro de la mentalidad indígena, el canto de los sapos y ranas augura 
un tiempo favorable para la agricultura. Según el hmen de San Isidro Macyam, "los sapitos son los que van a llamar a los santos yumtsilo'ob, y a los chako'ob para que con su canto les avisen que ya es tiempo de llover" (ibid.,). El hmen del pueblo de Ichmul indica que la presencia de los sapos en la ritualidad "garantiza que los sagrados vientos, van a escuchar la petición y van a bajar por la gracia que se les ofrece en el santo cha'achaak" (ibid.,). Dentro de esta ceremonia los mayas proceden a hacer gestos y croar como sapos, imitando por ejemplo el sapo identificado como uo'y otro conocido como lec. Realizan sonidos onomatopéyicos imitando su croar (Tuz Chi 2009, p. 176). Como podemos apreciar, dentro de la cosmovisión maya, las ranas son unos de los animales encargados de anunciar las lluvias y de solicitar a los vientos que las traigan.

Pero no solamente los animales acuáticos están incluidos en este ritual. Según Villa Rojas (1995, p. 104), la ceremonia del Ch'a-Chak se emplea con el fin de atraer la buena voluntad de los patrones de la naturaleza, los yumtzilo'ob. Aparte de reproducir de manera mimética al mundo mediante un altar con forma de cuadrilátero, las ramas y plantas que se emplean para adornarlo son de naturaleza fría, pues lo que se desea atraer son las lluvias. Las personas que participan en el ritual representan a las deidades cuyos favores se solicitan y se imitan no solamente a animales acuáticos, sino también a las aves encargadas de anunciar la llegada de las lluvias (Villa Rojas 1995, p. 104).

Dentro de la tradición religiosa mesoamericana las aves han sido consideradas como mensajeras de augurios, tanto buenos como malos. Son también mensajeras sobre todo de calamidades y algunas son empleadas como agentes malignos por brujos y hechiceros para esparcir su mal. Es especialmente conocida la capacidad de búhos y lechuzas para anunciar la muerte. Pero entre los fenómenos que tanto sus acciones como sus cantos pueden predecir, se encuentra en un lugar especial la lluvia (Hull y Fergus 2011, p. 46).

De acuerdo con los trabajos de Hull y Fergus (2009a, 2009b, 2011), son varias las aves que con su canto pueden predecir la lluvia. Entre los indígenas mopán de Belice existen varias aves que anuncian la llegada de las lluvias. Entre éstas se encuentra la chachalaca (Ortalis vetula), cuyo canto anuncia que pronto lloverá (Hull y Fergus 2009a, p. 24). El canto del k'ok'ota', o mirlo pardo (Turdus grayi), anuncia que la lluvia es inminente si esta ave se encuentra descansando en un árbol (Hull y Fergus 2009a, p. 24). Cabe señalar también el tántalo americano (Mycteria americana), cuyo canto, creen los indígenas de Mopán, anuncia la llegada de las lluvias (Hull y Fergus 2009a, p. 24).

Entre los choles, existe la creencia de que los pájaros pueden anunciar la llegada de las lluvias. Son varias las aves que, de acuerdo con los campesinos choles, por su comportamiento o actitud, predicen la llegada de las tormentas. Entre éstos se encuentran el cuco ardilla (Piaya cayana), denominado ti' ap por estas comunidades, el cual anuncia que lloverá pronto cuando canta con un 
agudo chillido que suena como "piiiiich" (Hull y Fergus 2011, p. 47). Asimismo tenemos el carpintero marrón (Veniliornis fumigatus) y el carpintero de frente dorada (Melanerpes aurifrons), ambos denominados $(x) t i$ : cuando alguno de ellos canta ' $t i$ ' $t i$ ' $t i$ "', las lluvias llegarán pronto (ibid.,). También el kel, o chachalaca es un ave cuyo canto "anuncia las lluvias" (Attinasi 1973, p. 279). Y por el contrario, el ch'urukinkuj, o búho gritón (Megascops trichopsis), da señales con su canto de que el tiempo se va a componer, es decir, que dejará de llover. Entre los q'eqchi' de Belice, el mirlo pardo, llamado por éstos k'ook'ob, también anuncia que lloverá al día siguiente si canta por la noche.

Pero entre las aves que pueden predecir el tiempo destacan algunas rapaces, tales como águilas y gavilanes, por su poder de predicción de ciertos eventos, llegando hasta ser considerados "hechiceros alados", tales como el águila negra (xiik en tzutujil), la cual es considerada como un "sajorin", término ampliamente empleado en el área maya para designar a brujos o hechiceros porque poseen la capacidad de predecir eventos futuros y localizar agua (Hull y Fergus 2009b, p. 103). Como ya mencionamos al describir a las aves que aparecen en la cuenta larga, éstas poseen características de rapaces, como las aves aquí descritas.

Siguiendo con el análisis de la relación de los seres que representan los periodos de la cuenta larga maya, consideremos ahora la serpiente de agua. De acuerdo con Zamora (2008), las Noh Chan son serpientes relacionadas con las corrientes de agua producidas por las lluvias estacionales en muy diversas fuentes etnográficas. Hellmuth (1987) relacionó a este ser con las aguas subterráneas y el inframundo, aunque claramente esto depende del contexto de aparición de la serpiente. Wisdom (1961, p. 447-448) menciona que los ch'orties de Guatemala creen en unas serpientes gigantescas relacionadas con los caudales de agua y los fenómenos atmosféricos, pues ayudan a producir la lluvia. De acuerdo con Daniel Salazar Lama (com. pers. 2015), la serpiente acuática WITZ', es un ser dual, pues es una criatura que representa una corriente de agua y, a la vez, es la personificación de las aguas terrestres, algunas vinculadas con el espacio del inframundo. Es muy probable que la serpiente witz' sea el ancestro de los seres llamados chijchan entre los ch'orties (Coltman 2015; Stuart 2007). Estos seres habitan dentro de todo cuerpo de agua (Wisdom 1961) y su jefe, el Noj Chan, controla las lluvias y el viento (Girard 1962, p. 116).

El cuerpo de la serpiente, generalmente ondulante y con una hilera de puntos que indican agua, parece representar una corriente, lo cual concuerda con lo propuesto por Stuart (2007) a partir de la lectura de su nombre. Por otro lado, en el mural poniente de San Bartolo se le ve con cuerpo antropomorfo, como un propiciador del renacimiento del dios del maíz. En este contexto espacial, dentro del caparazón de la tortuga, podría estar más asociada con el inframundo, como la personificación de las aguas de ese ámbito. Es así como se puede concluir que la serpiente WITZ', representa las corrientes de agua generadas a partir de las lluvias, las cuales asemejan gigantescas serpientes. 
Hemos podido descubrir que el factor común de los animales presentes en la cuenta larga hasta ahora analizados, es su capacidad de predecir o provocar la lluvia, y de manifestar su resultado. De ser esto cierto, faltaría ver cuál es la relación del mono con la lluvia.

Aunque muy pocas fuentes etnográficas suelen hablar del entorno natural, y si lo hacen no suelen especificar todos los animales de la región analizada sino solamente aquellos que tienen un marcado uso religioso, es muy conocido en las comunidades mayas que los monos aúllan o gritan cuando se aproxima una fuerte tormenta. Esto lo he podido constatar en campo, durante los trabajos de análisis epigráfico realizados para el Proyecto Arqueológico Calakmul, bajo la dirección del arqueólogo Ramón Carrasco Vargas. El mono, ya sea el saraguato o bien el araña, reaccionan ante eventos pluviales de cierta magnitud y lo hacen con muy poco tiempo de anticipación, pues con pequeñas lloviznas su actividad no se ve modificada. Sólo reaccionan de forma estentórea cuando se aproxima una fuerte tormenta acompañada de viento, gritando y agitando las ramas de los árboles.

Existen en realidad pruebas de que otros pueblos prehispánicos de Mesoamérica se dieron cuenta de esta relación entre el mono y las lluvias, si bien de manera indirecta, a través de la relación entre el mono y el viento, elemento este último necesario para la llegada de las tormentas (Gutiérrez Usillos 2002, p. 331-332; Nájera 2015, p. 145-160). Durante la realización de los trabajos de creación de la línea 1 del Metro de la Ciudad de México en 1967, se encontró un adoratorio dedicado al dios mexica del viento, Ehecatl-Quetzalcoatl, en lo que ahora es la estación del metro de Pino Suárez (Gussinyer 1969a, 1969b). Como parte de las ofrendas de dedicación del edificio, se localizó la estatua de un mono con la máscara bucal de Ehecatl (Figura 17).

De acuerdo con Beyer (1963), existen también figurillas de barro con la imagen de un mono con atributos de Ehecatl y, de acuerdo con este autor, los antiguos mexicanos identificaban al mono como el "soplador". Es decir, una de las advocaciones de Ehecatl-Quetzalcoatl era el mono, lo cual relaciona a este animal con el viento, elemento fundamental para acarrear las nubes que traen las tormentas.

Otro evento mitológico relaciona a los monos con el viento: es el narrado en la Leyenda de los Soles,

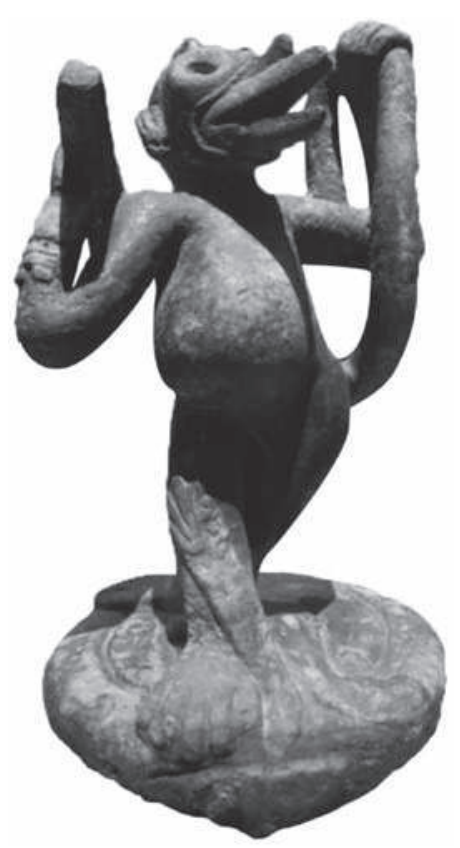

Fig. 17 - Estatua de la deidad Ehecatl-Ozomatli (foto S. Éliès). 
donde se indica claramente que, durante el segundo sol, el Nauhuecatl (4 viento), los que moraron en el mundo fueron llevados por el viento y convertidos en monos (Feliciano Velázquez 1992, p. 119).

Esta relación entre el mono y el viento también fue constatada por los antiguos pueblos mayas, como lo demuestra la presencia de un friso con estos animales en el conjunto arquitectónico de la Serie Inicial en Chichén Itzá (Nájera 2012), el cual, según Taube, estaba dedicado al Dios del Viento debido a la presencia de un ser

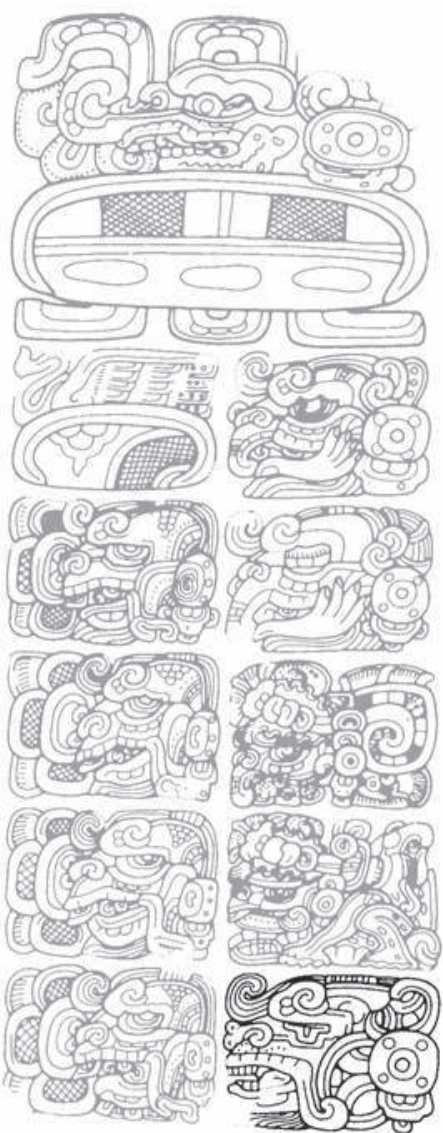

Fig. 18 - Estela 63 de Copán. El glifo del día, un mono con el signo del viento, $I k$ ', en el ojo, está aquí resaltado (según el dibujo de Barbara Fash). alado y con máscara en forma de pico en la Fachada del Osario (Taube 2015).

Ahora bien, otra evidencia de esta relación entre los monos y las deidades del viento en el área maya la podemos encontrar dentro del contexto de la propia cuenta larga. En algunos de los ejemplos de la utilización del mono como símbolo del día, podemos apreciar que dentro del ojo porta el símbolo en forma de “ $T$ ", leído como IK', mediante el cual se representa al viento en la cultura maya. Tal es el caso de la Estela 63 de Copán (Figura 18) y de la placa de Leiden (Figura 4).

La relación entre la presencia de los vientos y la lluvia en la cosmovisión mesoamericana la describía ya Sahagún, pues decía, con respecto a Quetzalcoatl que: "barría el camino a los dioses del agua y esto adivinaban porque antes que comienzan las aguas hay grandes vientos y polvos y esto decían que Quetzalcoatl, dios de los vientos, barría los caminos a los dioses de la lluvia, para que viniese a llover" (Gutiérrez Usillos 2002, p. 331). Esta relación entre la lluvia y el viento se ve reforzada en el caso del EhecatlOzomatli, al haber sido hallada también, como parte de las ofrendas del adoratorio de la estación del metro Pino Suárez, una estatua estucada y pintada de azul de un sapo (Figura 19), idéntico a los sapos ya citados del Templo Mayor (ver Figura 16). 


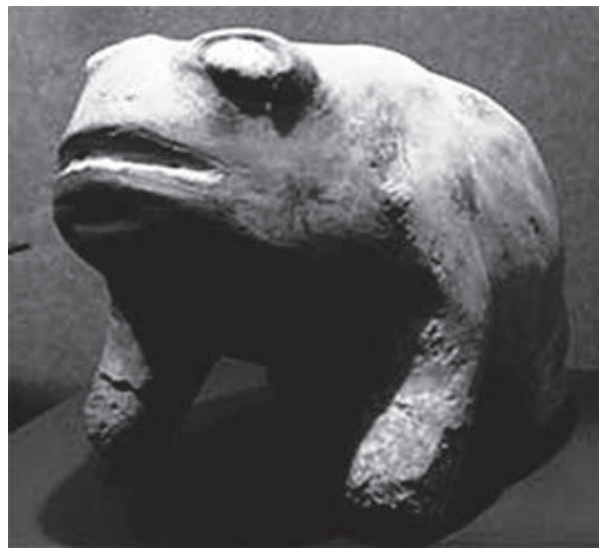

Fig. 19 - Estatua estucada y pintada con la forma de un sapo procedente de la ofrenda del adoratorio de Ehecatl en la estación del metro Pino Suárez de México (según Gussinyer 1969a).

\section{La lluvia, el viento, el año y los animales}

Llegados a este punto y después de haber realizado un análisis detallado de la carga simbólica que, dentro de las culturas de Mesoamérica, tienen los animales que se emplearon para representar los diferentes periodos que conforman la cuenta larga entre los mayas, se puede asegurar que el elemento común, el que da coherencia y consigue darle una lógica a su empleo, es el poder que dichos seres tenían para favorecer, predecir o anunciar la llegada de las lluvias, o ser producto de las mismas, como es el caso de la serpiente de agua.

Esto resulta de sumo interés porque indicaría que el objetivo primario de la creación de esa cuenta de los tiempos hubiera sido seguir las distintas épocas en las que se desarrollan las lluvias, muy en la línea del calendario egipcio antiguo cuya misión era el seguimiento de las subidas anuales del río Nilo (Duncan 1999, p. 32).

Los eventos meteorológicos tienen una periodicidad anual ampliamente reconocida en muchas partes del mundo, la cual está relacionada con la presencia de las estaciones. A partir del momento en que las culturas del pasado se volvieron sedentarias y dependientes de la agricultura, la necesidad de detectar la época correcta en la que se presentarían las lluvias llevó a los hombres a buscar signos entre los elementos de la naturaleza que tenían a mano, entre los cuales se encuentran los animales que les rodean, cuya interacción con el medio ambiente puede resultar en muchos casos más estrecha que la nuestra. De esas observaciones y de las necesidades surgidas por la dependencia de la agricultura es muy posible que surgieran los diversos calendarios en el mundo, entre ellos el mesoamericano, así como los signos que lo integran (Duncan 1999, p. xvi). 
Es así como los animales que representan los periodos de la cuenta larga serían vestigios de los medios a través de los cuales los mayas trataron de hacerse con el control de la pronosticación de la llegada de las aguas. Esto se percibe también a través del significado del propio nombre para el año, haab', palabra que parece derivar de ha', "lluvia" (Stuart 2011, p. 108; Thompson 1950, p. 144), elemento fundamental sobre el que basan los procesos relacionados con la agricultura.

Esta relación entre las palabras para designar el año y la lluvia se puede aún apreciar a nivel léxico en casi todas las lenguas mayas. Es así como la palabra para designar el año en la mayor parte de dichas lenguas se correspondería con el término empleado por los mayas del periodo clásico, haab', tal y como se puede apreciar en la siguiente tabla ${ }^{5}$ :

\begin{tabular}{|c|c|c|c|}
\hline Lengua & Vocablo $^{3}$ & Traducción & Fuente \\
\hline Ch'olti & $h a b$ & “año" & $\begin{array}{l}\text { Robertson et al. } 2010 \text {, } \\
\text { p. } 298\end{array}$ \\
\hline Ch'ortí & jab' & "edad, tiempo, año" & $\begin{array}{l}\text { Pérez Martínez et al. 1996, } \\
\text { p. } 76\end{array}$ \\
\hline $\begin{array}{l}\text { Chontal } \\
\text { (de Acalan) }\end{array}$ & $\begin{array}{l}j a b \\
-j a b\end{array}$ & $\begin{array}{l}\text { "año" } \\
\text { "clasificador numeral de } \\
\text { años por venir" }\end{array}$ & Smailus 1975, p. 141 \\
\hline $\begin{array}{l}\text { Chontal } \\
\text { (de Tabasco) }\end{array}$ & $j a b$ & "año" & $\begin{array}{l}\text { Keller y Luciano } 1997, \\
\text { p. } 125\end{array}$ \\
\hline Ch’ol & jab & "año" & Becerra 1937, p. 11 \\
\hline Chol (de Tila) & jabil & “año" & Schumann 1973, p. 47 \\
\hline Tzotzil & jabil & “año" & $\begin{array}{l}\text { Laughlin 2007, p. 89; } \\
\text { Hurley y Ruíz 1986, p. } 57\end{array}$ \\
\hline Tzotzil colonial & jabil & “año" & $\begin{array}{l}\text { García de León } 1971, \\
\text { p. } 48\end{array}$ \\
\hline Tzeltal & ha'bil & "año" & Kaufman 1972, p. 103 \\
\hline $\begin{array}{l}\text { Tzeltal } \\
\text { (de Bachajon) }\end{array}$ & habil & "año" & $\begin{array}{l}\text { Slocum y Gerdel 1991, } \\
\text { p. } 19\end{array}$ \\
\hline Mopán & jaab & "año" & Schumann 1997, p. 217 \\
\hline Yucateco & $\begin{array}{l}\text { hab } \\
\text { habil }\end{array}$ & $\begin{array}{l}\text { "año" } \\
\text { "edad en la que se hace } \\
\text { algo" }\end{array}$ & Swadesh et al. 1991, p. 50 \\
\hline
\end{tabular}

Tabla 1 - Palabra con la que se designa el año en las lenguas mayas.

5. A lo largo del presente trabajo se respeta la ortografía usada por cada diccionario referenciado. 
Pero en algunos casos, para ciertas lenguas mayas, la misma palabra designa las lluvias:

\begin{tabular}{|l|l|l|l|}
\hline \multicolumn{1}{|c|}{ Lengua } & Vocablo & \multicolumn{1}{c|}{ Traducción } & \multicolumn{1}{c|}{ Fuente } \\
\hline Achi & jab' & "Iluvia" & Tuyuc Sucuc 2000, p. 41 \\
Quiche & $h a b$ & $\begin{array}{l}\text { "rainstorm, downpour, } \\
\text { hard rain" }\end{array}$ & Edmonson 1965, p. 37 \\
Pok'om & $\begin{array}{l}\text { "rain" } \\
\text { habih }\end{array}$ & $\begin{array}{l}\text { "año [dícenlo] como } \\
\text { "el aguacero", un año" }\end{array}$ & Acuña 1991, p. 267 \\
\hline
\end{tabular}

Tabla 2 - Palabra con la que se designa la lluvia en algunas lenguas mayas.

Resulta de especial interés la entrada para hab en la lengua pok'om, pues nos indica que ambos términos eran equiparables o sinónimos.

Ya algunos de los cronistas coloniales indican esta manera de conceptualizar el año basándose en las épocas de lluvias. Ciudad Real (1976, vol. 1, p. 55) nos dice en relación con las tierras del México central: "Las aguas comienzan en aquella provincia ordinariamente por mayo, y se acaban ordinariamente por nuestro padre San Francisco (4 de octubre), y a este tiempo llaman invierno; en los demás meses no llueve de ordinario, y a este llaman verano".

Resulta también interesante constatar que, en algunos casos, el poder predictivo es directo, como en el caso de batracios y pájaros, pues los comportamientos de estos animales están claramente regidos por los ciclos estacionales relacionados con las lluvias. En el caso de la serpiente de agua, la relación es más conceptual, ya que, dentro de la cosmovisión indígena maya, estas serpientes gigantes que viven dentro de la tierra ayudan a los dueños del mundo a traer las lluvias para proveer a plantas, animales y a los propios hombres.

El caso que a priori parece más peculiar es el de los monos, ya que son pocos los vestigios que señalan que estos animales tienen una relación especial con la lluvia dentro de las creencias de los pueblos de Mesoamérica. Su comportamiento resulta muy llamativo en el momento en el que va a comenzar a llover. Cuando una tormenta se acerca en las zonas selváticas del área maya, lo primero que se puede percibir es un fuerte viento. Este viento anuncia que la tormenta es inminente y cuanto mayor sea la tormenta, más fuerte será el viento. Cuando el viento de tormenta comienza a soplar, los monos se agitan, gritan y se mueven sacudiendo las ramas que tienen a su alcance; una vez que comienza la tormenta, se calman y esperan a que pase para seguir moviéndose entre las diferentes zonas en las cuales se alimentan. Es decir, en realidad reaccionan ante el viento, de ahí que los mayas y otros pueblos mesoamericanos los hayan relacionado con este fenómeno atmosférico. Por tanto, la relación entre viento 
y lluvia dentro de la cosmovisión mesoamericana es muy estrecha. Son los vientos los que traen la lluvia, son ellos los que traen las tormentas.

La selección de la correspondencia entre cada animal y cada unidad de la cuenta larga, puede deberse a las diferentes capacidades predictivas de los animales empleados. Como ya se ha indicado, los monos se agitan cuando el aire que acompaña a las tormentas comienza a soplar; éste es un hecho casi inminente que se puede predecir solamente por unos cuantos minutos. En cambio, los batracios pueden predecir si va llover con uno o dos días de antelación. Esto se debe a que poseen una especial sensibilidad a los cambios atmosféricos, en especial a los cambios barométricos (Duellman y Trueb 1994), lo que les permite comenzar con los llamados a las hembras con el fin de aparearse cuando se aproximan las lluvias (Marsh 2000; Oseen y Wasserung 2002). Pero los animales que son especialmente sensibles a los cambios de presión atmosférica son las aves, pues pueden detectar cambios de altitud de hasta $10 \mathrm{~m}$ (O’Neill 2013). Esta sensibilidad les permite predecir cuándo se aproximan los cambios estacionales, con el fin de poder comenzar sus periodos de migración y esto obviamente incluye la proximidad de la época de lluvias (Keeton 1999). Es así como parece que los animales fueron ordenados de acuerdo con el tiempo de anticipación con el que pueden predecir la proximidad de las lluvias, yendo del que menos capacidad tiene, al que posee la mayor capacidad predictiva.

Así mismo, el empleo de aves para los tres periodos superiores puede deberse a que en un principio la cantidad de los mismos era de solamente tres periodos, siendo un vestigio de esto el empleo de pik como nombre de un periodo que no se corresponde con la cantidad de días que enumera. Posiblemente, en sus orígenes, el calendario efectivamente sólo contaba años. Con el avance de la civilización y de la cultura, la necesidad de elevar la cuenta a periodos de años requirió la inclusión de nuevos elementos en la cuenta larga, para los cuales se empleó el último animal presente en la misma, con alguna modificación que les pudiera diferenciar entre sí. Se requerirá de mayor información, especialmente temprana, para poder corroborar esta hipótesis.

Una vez más se puede apreciar cómo, a pesar de que los elementos iconográficos que conforman el conjunto de creencias de un pueblo, en este caso el maya, pueden tener múltiples valores simbólicos, el contexto de empleo de dichos elementos nos indica cuál es el valor primario que se debe aplicar al símbolo en cada caso (Valencia 2015). A pesar de que aves, serpientes, batracios y monos poseen múltiples valores simbólicos dentro de la tradición cultural maya, en la representación de los periodos de la cuenta larga, el valor simbólico primario que sobresale es la relación que en conjunto todos tienen con la temporada de lluvias, periodo que permite demarcar el año solar.*

* Manuscrit reçu en septembre 2015, accepté pour publication en octobre 2015.

Este artículo forma parte del número especial Compases y texturas del tiempo entre los mayas: lo dicho, lo escrito, lo vivido. 
El tiempo vuela: el uso de aves y otros animales

\section{Referencias citadas}

AcuÑa Andrés

1991 Arte breve y Vocabularios de la lengua pokom. Basado en los manuscritos de fray Pedro Morán y fray Dionisio de Zúñiga. UNAM, Instituto de Investigaciones Filológicas, Filología, Gramáticas y Diccionarios 5, México.

AtTinASi John

1973 Lak T'an. A Grammar of Chol (Mayan), University of Chicago, Chicago.

Ayala Maricela

1983 "El origen de la escritura jeroglífica maya", in Lorenzo Ochoa y Thomas A. Lee (eds), Antropología e historia de los mixe-zoques y mayas. Homenaje a Frans Blom, Instituto de Investigaciones Filológicas, UNAM, México p. 175-221.

BAKER Mary

1992 "Capuchin Monkeys (Cebus capucinus) and the Ancient Maya", Ancient Mesoamerica, 3, p. 219-228.

Barrera VÁsquez Alfredo

1980 Diccionario Maya Cordemex. Maya-Español, Español-Maya, Ediciones Cordemex. Mérida.

BeCERRA Marcos E.

1937 Vocabulario de la lengua Chol. Secretaria de Educación Pública. Publicaciones del Museo Nacional de México, México.

BEYER Hermann

1963 Mito y simbolismo del México Antiguo. El México Antiguo, Tomo X, México. BRAAKHUIS H. Edwin M.

1987 "Artificers of the days: Functions of the Howler Monkey Gods among the Mayas", Bijdragen Tot de Taal-, Land- en Volkenkunde, deel 143, p. 25-53.

BECERRA Marcos E.

1937 Vocabulario de la lengua Chol, Secretaria de Educación Pública, Publicaciones del Museo Nacional de México, México.

Cases Ignacio, Alfonso Lacadena, Philippe Nondédéo

2014 "El uso del tiempo en la narrativa de Naachtun del periodo Clásico", in Mesures et textures du temps chez les Mayas : le dit, l'écrit, le vécu, Colloque international interdisciplinaire, musée du quai Branly, 8, 9 y 10 de octubre de 2014, Paris.

Ciudad Real Antonio de

1976 Tratado curioso y docto de las grandezas de la Nueva España, Josefina García Quintana y Víctor M. Castillo Farreras (eds), Instituto de Investigaciones Históricas, UNAM, México, 2 vols.

Coe Michael

1977 "Supernatural Patrons of Maya Scribes and Artists", in Norman Hammond (ed.), Social Process in Maya Prehistor, Academic Press, Londres, p. 327-347.

Coltman Jeremy D.

2015 'In The Realm of the Witz': Animate Rivers and Rulership among the Classic Maya", The PARI Journal, 15 (3), p. 5-30. 
DAVLETSHIN Albert

2002 "Once upon a time there was no zero. Evolution of South-Eastern Mesoamerica's calendric notation", in M. Kõiva, H. Mürk e I. Pustõlnik (eds), Cultural Context from the Archaeoastronomical Data and the Echoes of Cosmic Events, Abstracts submitted for the SEAC 2002 10th Annual Conference, 27-30 August, Tartu, Estonia, p. 25-26.

Duellman W.E. y L. TRueB

1994 Biology of Amphibians, McGraw-Hill, New York.

DunCAN David Ewing

1999 The Calendar. The 5000 Year Struggle to Align the Clock and the Heavens and What Happened to the Missing Ten Days, Forth State, Londres.

EDMONSON Munro S.

1965 Quiche-English Dictionary, Middle American Research Institute, Tulane University, Nueva Orleans.

Feliciano VelázQuez Primo

1992 Códice Chimalpopoca. Anales de Cuauhtitlán y Leyenda de los Soles, Instituto de Investigaciones Históricas, UNAM, México.

García de LeÓn Antonio

1971 Los elementos del tzotzil colonial y moderno, Centro de Estudios Mayas, Cuaderno 7, UNAM, México.

GIRARD Rafael

1962 Los mayas eternos, Antigua Librería Robredo, México.

GussinYER Jordi

1969a "Hallazgos en el Metro, Conjunto de Adoratorios Superpuestos en Pino Suárez”, Boletín INAH 36, Junio, p. 33-37.

1969b "Una Escultura de Ehecatl-Ozomatli", Boletín INAH 37, Septiembre, p. 29-32. GuTIÉRREZ UsiLlos Andrés

2002 Dioses, símbolos y alimentación en los Andes: interrelación hombre-fauna en el Ecuador prehispánico, Editorial Abya-Yala, Quito.

Hellmuth Nicholas

1987 Monster und Menschen in der Maya-Kunst, Adeva, Graz.

Hull Kerry y Rob Fergus

2009a “An Ethno-Ornithological Approach to Human-Bird Relations", Conference Proceedings of the 8th Annual Hawaii International Conference on Social Science, June 4-7, 2009, Honolulu, HI., p. 17-31.

2009b "Eagles in Mesoamerican Thought and Ideology", Reitaku Review, vol. 15, p. 85-134.

2011 "Ethno-ornithological Perspectives on the Ch'ol Maya", Reitaku Review, 17, p. 42-92.

Hurley Alfa y Agustín Ruíz SÁnchez

1986 Diccionario tzotzil de San Andrés con variaciones dialectales, Instituto Lingüístico de Verano, México.

Jones Christopher y Linton SATterTHWAite

1982 The Monuments and Inscriptions of Tikal: The Carved Monuments, Tikal Report 33A, vol. 3, University of Pennsylvania Press. 
El tiempo vuela: el uso de aves y otros animales

Justeson John y Terrence KAUfMan

1992 "Un desciframiento de la escritura jeroglífica epi-olmeca: métodos y resultados", Arqueología, 8, p. 15-25.

Justeson John S., William M. Norman, Lyle Campbell y Terrence Kaufman

1985 The Foreign Impact on Lowland Mayan Language and Script. Middle American Research Institute Pub, 53, Tulane University, New Orleans.

KaUfMAn Terrence

1972 El proto-tzeltal-tzotzil, Centro de Estudios Mayas, Cuaderno 5, UNAM, México. KeEton William T.

1999 "The Orientation and Navigation of Birds", in D. J. Aidley (ed.), Animal Migration. Cambridge University Press, p. 87-88.

Keller Kathryn C. y Plácido Luciano G.

1997 Diccionario Chontal de Tabasco, Instituto Lingüístico de Verano, Tucson, Arizona.

LACADENA Alfonso

2010 "Historical Implications of the Presence of Non-Mayan Linguistic Features in the Maya Script", in Laura Van Broekhoven, Rogelio Valencia Rivera, Benjamin Vis y Frauke Sachse (eds), The Maya and their Neighbours. Internal and External Contacts Through Time, Acta Mesoamericana 22, Verlag Anton Saurwein, Markt Schwaben, Alemania, p. 29-39.

2011 "On the Origin and Nature of Mesoamerican Writing Systems", Ponencia presentada en 6th European Maya Conference, Copenhagen, Denmark.

Lacadena Alfonso, Sebastian Matteo, Asier Rodríguez Manjavacas, Hugo García Capistrán, Rogelio Valencia Rivera y Nacho Cases Marín

2010 "Introducción a la escritura jeroglífica maya", Cuaderno de Trabajo 2, $15^{\mathrm{a}}$ Conferencia Maya Europea, Museo de América, Madrid.

LACADENA Alfonso y Soren WichmanN

2002 "The Distribution of Lowland Maya Languages in the Classic Period", in Vera Tiesler, Rafael Cobos y Merle Greene Robertson (eds), La Organización social entre los mayas: Memoria de la tercera Mesa Redonda de Palenque. vol. 2, Instituto Nacional de Antropología e Historia, México, p. 275-320.

LAUGHLIN Robert

2007 El gran diccionario tzotzil de San Lorenzo Zinacantán, Centro de Investigaciones y Estudios Superiores en Antropología Social. Dirección General de Culturas Populares, México.

López Austin Alfredo y Leonardo LóPEZ LuJÁN

2011 Monte sagrado-Templo Mayor. El cerro y la pirámide en la tradición religiosa mesoamericana, Instituto Nacional de Antropología e Historia, Instituto de Investigaciones Antropológicas, UNAM, México.

LOUNSBURY Floyd

1978 "Maya Numeration, Computation, and Calendrical Astronomy", in Charles C. Gillispie (ed.), Dictionary of Scientific Biography, Charles Scribner's Sons, New York, p. 759-818.

Marsh D. M.

2000 "Variable Responses to Rainfall by Breeding Tungara Frogs", Copeia, 4, p. 1104-1108. 
MARTin Simon

2000 "At the Periphery: The Movement, Modification and Re-use of Early Monuments in the Environs of Tikal", in P. R. Colas, K. Delvendahl, M. Kuhnert y A. Pieler (eds), The Sacred and the Profane: Architecture and Identity in the Southern Maya Lowlands, Acta Mesoamericana 10, Markt Schwaben, Hamburg, p. 51-62.

Milbrath Susan

1999 Star Gods of the Maya. Astronomy in Art, Folklore, and Calendars. University of Texas Press, Austin.

NÁJERA Coronado Martha Ilia

2012 "El mono y el cacao: la búsqueda de un mito a través de los relieves del grupo de la Serie Inicial de Chichén Itzá", Estudios de Cultura Maya XXXIX, p. 133-172.

2015 Dioses y seres del viento entre los antiguos mayas, UNAM, Instituto de Investigaciones Filológicas, México.

O’NeILl Paul

2013 "Magnetoreception and Baroreception in Birds", Develop. Growth Differ, 55, p. 188-197.

Oseen Kerri L. y Richard J. WAsserung

2002 "Environmental Factors Influencing Calling in Sympatric Anurans". Oecologia, 133, p. 616-625.

Pérez Martínez Vitalino, Federico García, Felipe Martínez y Jeremías LóPez

1996 Diccionario del idioma Ch'orti'. Diccionario Ch'orti' Jocotan, Chiquimula, Proyecto Lingüístico Francisco Marroquín, La Antigua, Guatemala.

PÉrez SuÁrez Tomas

2012 "La escritura istmeña o epi-olmeca como antecedente de la maya: una revisión histórica", http://www.revista.unam.mx/vol.13/num11/art106/index.html

Rice Prudence M.

2007 Maya Calendar Origins. Monuments, Myth, History, and the Materialization of Time, University of Texas Press, Austin.

Rivera Castillo Patricia y William A. Saturno

2012 Proyecto Arqueológico Regional San Bartolo-Xultun. Informe de resultados de investigaciones temporada de campo, vol. 11, Instituto de Antropología e Historia de Guatemala, Guatemala.

Robertson John S., Danny Law y Robbie A. Haertel

2010 Colonial Ch'olti'. The Seventeenth-Century Morán Manuscript, University of Oklahoma Press, Norman.

Salazar Lama Daniel

2014 Ajk'an Witz. Montañas, antepasados y escenas de resurrección en el friso de Balamkú, Campeche, tesis de maestría. Posgrado en Estudios Mesoamericanos, Facultad de Filosofía y Letras, UNAM, México.

Schumann G. Otto

1973 La lengua Chol, de Tila (Chiapas), Centro de Estudios Mayas, Cuaderno 8, UNAM, México. 
1997 Introducción al maya mopán. Los itzáes desde la época prehispánica hasta la actualidad, estudio interdisciplinario de un grupo maya, Instituto de Investigaciones Antropológicas, UNAM, México.

SLocum Marianna C. y Florencia L. Gerdel

1991 Vocabulario tzeltal de Bachajon. Centro de Estudios Mayas, Cuaderno 3, UNAM, México.

SMAILus Ortwin

1975 El maya-chontal de Acalan. Análisis lingüístico de un documento de los años 1610-1612, Centro de Estudios Mayas, Cuaderno 9, UNAM, México.

Stuart David

1996 "Kings of Stone. A Consideration of Stelae in Ancient Maya Ritual and Representation". RES: Anthropology and Aesthetics, 29/30 Spring/Autumn, p. 149-171.

2007 Reading the Water Serpent as WITZ', Maya Decipherment, Blog personal, https://decipherment.wordpress.com/2007/04/13/reading-the-water-serpent/

2011 The Order of Days. The Maya World and the Truth about the 2012, Harmony Books, New York.

2012 Bak'tuns and More Bak'tuns. Maya Decipherment, Blog personal, https:// decipherment.wordpress.com/2012/12/19/baktuns-and-more-baktuns/

2014 Notes on a Sacrifice Scene. Maya Decipherment, Blog personal, https:// decipherment.wordpress.com/2014/10/31/notes-on-sacrifice-scene/

Swadesh Mauricio, Ma. Cristina Àlvarez y Juan R. BAstarracheA

1991 Diccionario de elementos del maya yucateco colonial, Instituto Lingüístico de Verano, México.

TAuBE Karl

2003 "Maws of Heaven and Hell: The Symbolism of the Centipede and Serpent in Classic Maya Religion", in Andrés Ciudad Ruíz, Mario Humberto Ruz Sosa y Ma. Josefa Iglesias Ponce de León (eds), Antropología de la eternidad: la muerte en la cultura maya, Sociedad Española de Estudios Mayas, Madrid, p. 405-442.

2015 "The Initial Series Group at Chichén Itza, Yucatan: Recent Studies and Interpretations", in Symposium Mesoamericano en honor a Linda Schele. In the Realm of the Vision Serpent: Decipherments and Discoveries in Mesoamerica. 10 y 11 de abril de 2015, Los Angeles, California.

Tellenbach Michael

1977 “Algunas consideraciones sobre la 'Estela C' y su complemento, la 'Estela Covarrubias', de Tres Zapotes, Veracruz”, Indiana, 4, p. 63-74.

THOMPSON J. Eric S.

1950 Maya Hieroglyphic Writing: An Introduction. University of Oklahoma Press, Norman.

1962 A Catalog of Maya Hieroglyphs. University of Oklahoma Press, http://www. famsi.org/mayawriting/thompson/

TOKOVININE Alexandre

2013 3D Imaging Report. Corpus of Maya Hieroglyphic Inscriptions, https://www. peabody.harvard.edu/node/821 
Tuyuc Sucuc Alexandre

2000 Vocabulario Achi. Academia de Lenguas Mayas de Guatemala, Comunidad Lingüística Achi, Guatemala.

Tuz CHI Lázaro Hilario

2009 Así es nuestro pensamiento. Cosmovisión e identidad en los rituales agrícolas de los mayas peninsulares, tesis de doctorado, Universidad de Salamanca, Instituto de Iberoamérica, Facultad de Ciencias Sociales, Salamanca, España.

VALENCIA Rivera Rogelio

2013 "Las múltiples caras de la divinidad. Complejos de dioses en la religión maya", in Alejandro Sheseña (ed.), Religión maya: rasgos y desarrollo histórico. Unicach, Tuxtla Gutiérrez, México, p. 225-238.

2015 “A picture is worth a thousand words. Or not?", in Harri Kettunen y Christophe Helmke (eds), On Methods: How we Know what We Think We Know about the Maya, Acta Mesoamericana 28, Verlag Anton Saurwein, Markt Schwaben, p. 91-99.

Valencia Rivera Rogelio y Daniel Salazar Lama

2017 "El ave como cielo: la presencia del ave CHAN en las bandas celestes mayas", Journal de la société des américanistes, 103-2, p. 9-45.

Villa Rojas Alfonso

1995 Estudios etnológicos. Los mayas, UNAM, México.

Weathers Kenneth y Nadine Weathers

1949 Diccionario español-tzotzil, tzotzil-español, Instituto Lingüístico de Verano, México.

Wells Kentwood D.

2007 The Ecology and Behavior of Amphibians, The University of Chicago Press, Chicago.

WisDom Charles

1950 Ch'orti Dictionary, Transcrito por Brian Stross, University of Texas at Austin, Texas.

1961 Los chortís de Guatemala, Seminario de Integración Social Guatemalteca 10, Editorial José de Pineda Ibarra, Guatemala.

Zamora Moya María Auxiliadora D.

2008 La Serpiente de Agua en el periodo Clásico maya, Trabajo de investigación de Doctorado del departamento de Historia de América II (Antropología de América) de la facultad de Geografía e Historia de la Universidad Complutense de Madrid, Madrid. 